\title{
EVALUASI KRIM ANTIOKSIDAN SOLID LIPID MICROPARTICLE EKSTRAK ETANOL DAUN KERSEN (MUNTINGIA CALABURA L.)
}

\section{ANTIOXIDANT CREAM EVALUATION OF SOLID LIPID MICROPARTICLES KERSEN'S LEAVES ETHANOL EXTRACT}

\author{
Amriani Sapra, Radhia Riski, Besse Jamila \\ Sekolah Tinggi IImu Farmasi Makassar
}

E-mail korespondensi : amriani.sapra@gmail.com

\begin{abstract}
Kersen (Muntingia calabura L.) leaves is a plant that contains flavonoids as antioxidants which can be formulated in Solid Lipid Microparticle. The aim of this study is to make Solid Lipid Microparticle cream loaded ethanol extract of kersen leaves preparation and evaluated it's physical stability. Solid Lipid Microparticle was made of $3 \%$ kersen leaves ethanol extract with entrapment efficiency $85.75 \%$ formulated in cream preparation with variation of cetyl alcohol concentration namely F1 (2\%), F2 (4\%), F3 (6\%). Creams then tested it's stability before and after accelerated storage using climatic chamber. In $\mathrm{pH}$ measurement, there are change in $\mathrm{pH}$ value after accelerated condition in all formulas but still in required range 4.5-6.5. Evaluation in viscosity showed viscosity increase from F1, F2 and F3 depend on concentration of cetyl alcohols. In sticky and spreadability testing, sticky ability decrease and spreadability increase after accelerated condition in all formulas in chage of viscosity. Type of emulsion evaluation showed no phase invertion after accelerated and remain in $\mathrm{o} / \mathrm{w}$ state. The results showed that the three formulas fulfilled the quality of preparation with organoleptic, homogenity, type of cream, viscosity, $\mathrm{pH}$, sticky and spreadability parameters before and after accelerated conditions.
\end{abstract}

Keywords : Kersen leaves, Muntingia calabura, SLM Cream

\section{ABSTRAK}

Kersen (Muntingia calabura L.) merupakan salah satu tanaman yang mengandung flavonoid yang berfungsi sebagai antioksidan. Penelitian ini bertujuan untuk membuat krim solid lipid microparticle(SLM) ekstrak etanol daun kersen dan mengetahui kestabilan fisiknya. SLM yang dibuat dari ekstrak etanol daun kersen 3\% dengan efisiensi penjerapan $85,75 \%$ diformulasi dalam bentuk krim dengan variasi konsentrasi setil alkohol yaitu F1 (2\%), F2 (4\%), F3 (6\%). Krim kemudian dilakukan uji stabilitas sebelum dan sesudah penyimpanan dipercepat dengan climatic chamber. Pada pengukuran $\mathrm{pH}$, terjadi perubahan $\mathrm{pH}$ setelah pengujian dipercepat pada semua formula namun masih berada dalam range $\mathrm{pH}$ yang dipersyaratkan 4,5-6,5. Pengujian viskositas menunjukkan terjadi peningkatan viskositas dari $\mathrm{F} 1$, F2 dan F3 berdasarkan peningkatan konsentrasi setil alcohol. Pada pengujian daya sebar dan daya lekat, terjadi peningkatan daya sebar dan penurunan daya lekat setelah pengujian dipercepat pada ketiga formula sehubungan dengan perubahan viskositas. Pada pengujian tipe emulsi juga tidak terjadi inverse fase setelah penyimpanan dipercepat yaitu krim tipe $\mathrm{m} / \mathrm{a}$. Hasil penelitian menunjukkan bahwa ketiga formula memenuhi mutu sediaan dengan parameter yakni organoleptik, homogenitas, tipe krim, viskositas, $\mathrm{pH}$, uji daya lekat, dan uji daya sebar dengan baik sebelum maupun sesudah penyimpanan dipercepat.

Kata kunci : Daun kersen, Krim SLM, Muntingia calabura

\section{PENDAHULUAN}

Radikal bebas merupakan suatu atom atau molekul yang tidak stabil dan sangat reaktif karena mengandung satu atau lebih elektron tidak berpasangan pada orbital terluarnya (Sami et al., 2017). Radikal ini cenderung mengadakan reaksi berantai yang dapat menimbulkan kerusakan yang terus-menerus. Sumber radikal bebas dapat berasal dari dalam tubuh (endogen) yang terbentuk sebagai sisa proses metabolisme, serta diperoleh dari luar tubuh (eksogen) yang berasal dari polusi udara, asap kendaraan dan sinar ultra violet (UV). Sinar UV sangat berbahaya bagi kulit karena reaksi yang ditimbulkan berpengaruh buruk terhadap kulit seperti kulit kemerahan, pigmentasi bahkan dalam jangka waktu lama dapat menyebabkan kanker kulit (Sari, 2015).

Antioksidan merupakan salah satu senyawa yang dapat mehambat radikal bebas, molekul yang tidak stabil yang dihasilkan oleh berbagai jenis proses kimia atau radiasi sinar ultra violet (UV) (Imrawati et al., 2017). Antioksidan dapat diperoleh dari dalam tubuh (endogen) seperti enzim yang bersifat antioksidan yaitu superoksida dismutase (SOD), katalase (Cat) dan glutathione peroksidase (Gpx), serta antioksidan yang berasal dari luar tubuh (eksogen) seperti vitamin C dan vitamin E (Sayuti \& Yenrina, 2014).

Tanaman tradisonal juga berperan menghambat radikal bebas, salah satunya yaitu tanaman kersen (Muntingia calabura 
L.). Berdasarkan hasil penelitian Puspitasari dan Wulandari (2017), daun kersen mengandung metabolit sekunder berupa flavonoid, saponin, polifenol dan tanin, berguna sebagai penangkal radikal bebas yang memiliki aktivitas sebagai antioksidan. Komponen senyawa flavanoid yang tertinggi dihasilkan oleh daun kersen yang diduga bersifat sebagai antioksidan yang kuat dengan nilai $\mathrm{IC}_{50}$ yaitu $18,214 \mathrm{ppm}$ (Kuntorini et al., 2013).

Kandungan senyawa flavonoid yang terkandung dalam daun kersen merupakan senyawa yang bersifat polar sehingga mengalami kesulitan berdifusi melalui kulit karena struktur kulit memiliki lapisan yang bersifat nonpolar. Pada umum antioksidan bekerja dilapisan dermis. Oleh karena itu dibutuhkan suatu sistem penghantaran topikal yang yang dapat menembus lapisan stratum korneum yang memiliki daya absorbsi yang optimal. Salah satu bentuk penghantaran dengan kemampuan tersebut yaitu solid lipid microparticle (SLM) (Roy et al., 2014).

Solid lipid microparticle (SLM) merupakan sistem penghantaran obat yang sesuai untuk menghantarkan sediaan topikal karena diketahui memiliki kemampuan untuk melindungi komponen senyawa flavonoid dan berfungsi sebagai pembawa untuk mengatur sistem penghantaran obat melalui pengembangan formula seperti emulsi, dengan ukuran ratarata partikel antara 18-45 $\mu \mathrm{m}$ (Chengyu et al, 2016).

Pada penelitian sebelumnya oleh Asdar (2017) tentang formulasi solid lipid microparticle (SLM) ekstrak etanol daun kersen (Muntingia calabura L.) menyatakan bahwa konsentrasi 3\% dapat memberikan efek antioksidan. Tujuan dari penelitian ini untuk memformulasi bentuk sediaan krim dari SLM 3\% ekstrak etanol daun kersen yang stabil.

\section{METODE}

\section{Desain, tempat dan waktu}

Penelitian dilakukan dimulai dari formulasi sediaan krim SLM yang dilanjutkan dengan uji stabilitasnya yang dilaksanakan di laboratorium Farmasetika dan Penelitian STIFA Makassar pada bulan Januari-Maret 2019

\section{Bahan dan alat}

Bahan yang digunakan adalah alfa tokoferol, aquadest, asam stearat, DMDM hydantoin, etanol $70 \%$, metilen blue, oleum rosae, paraffin cair, phenoxyetanol, propilenglikol, setil alkohol, span 60, solid lipid microparticle ekstrak etanol daun kersen (Muntingia calabura L.), tween 60.

Alat yang digunakan pada penelitian ini adalah alat-alat gelas (Pyrex®), cawan porselen, centrifuge (PLC series $®$ ), climatic chamber, freeze dryer (Coolsafe ${ }^{\mathrm{TM}}$ ), hot plate, kertas perkamen, lumpang dan stamper, magnetik stirrer (SSM 79-1@), pH meter, sendok tanduk, sonikator, stopwatch, termometer, timbangan analitik, viskometer $\left(\right.$ Brookfield $\left.^{\circledR}\right)$.

\section{Langkah- Langkah Penelitian Pembuataan Krim}

Fase minyak dibuat dengan melebur asam stearat, setil alohol, span 60, paraffin cair, dan phenoxy etanol pada suhu $70^{\circ} \mathrm{C}$. Fase air dibuat dengan memanaskan aquadest, propilenglikol, DMDM hydantoin dan tween 60 , pada suhu $80^{\circ} \mathrm{C}$. Diaduk dengan homogenizer sampai terbentuk basis krim. kemudian ditambahkan alfa tokoferol, oleum rosae dan solid lipid microparticle (SLM) sedikit demi sedikit sambil diaduk sampai homogen.

\section{Evaluasi Krim \\ Evaluasi Kestabilan Sediaan Krim}

Pengujian dlakukan menggunakan climatic chamber terdiri dari 1 siklus dengan suhu $5^{\circ} \mathrm{C}$ dan $35^{\circ} \mathrm{C}$ selama 12 jam dan dilakukan sebanyak 10 siklus (Voight, 1994). Pengujian yang dilakukan berupa:

\section{Uji Organoleptik}

Memeriksa kesesuaian warna, bau, tekstur dan melihat pemisahan fase pada krim (Fatmawaty et al., 2015).

\section{Uji Homogenitas Fisik}

Sejumlah krim dioleskan pada kaca objek yang bersih dan kering sehingga membentuk suatu lapisan yang tipis, kemudian ditutup dengan kaca preparat (cover glass) (Voight, 1994).

\section{Penentuan $\mathrm{pH}$}

$\mathrm{pH}$ krim diukur dengan menggunakan $\mathrm{pH}$ meter.

\section{Uji Viskositas}

Viskositas sediaan krim diukur menggunakan Viskometer Brookfield pada 3 rpm menggunakan "spindle" no. 64.

\section{Uji Daya Sebar}

Krim sebanyak 0,5 gram diletakkan ditengah-tengah kaca objek, ditutup dengan kaca objek yang telah ditimbang beratnya. Dibiarkan selama 1 menit kemudian diukur 
diameter sebar krim. Beban dinaikkan setiap 5 menit sebesar 50 gram sampai 250 gram (Swastika et al., 2013).

\section{Uji Daya Lekat}

Sebanyak 0,25 gram krim diletakkan pada salah satu gelas objek kemudian ditutup dengan objek yang lain. Selanjutnya ditindih dengan beban 50 gram selama 5 menit. Waktu melekat dihitung mulai dari pemberian beban dan dihentikan pada saat gelas objek tersebut terlepas (Genatrika, 2016).

Uji Tipe Emulsi

\section{Metode Pengenceran}

Krim dimasukkan kedalam gelas beaker, kemudian diencerkan dengan air. Jika emulsinya dapat diencerkan dengan air maka tipe emulsinya M/A (Lachman, 1994).

\section{Metode Dispersi Warna}

Krim diletakkan diatas gelas arloji dan ditetesi beberapa tetes pewarna metilen blue. Jika warna biru segera terdispersi keseluruhan maka sediaan krim tipe emulsinya M/A (Lachman, 1994).

\section{Pengolahan dan analisis data \\ Hasil data yang diperoleh dibandingkan dengan standar pada literature kemudian ditarik kesimpulan.}

\section{HASIL}

Dalam penelitian ini solid lipid microparticle (SLM) dibuat dalam bentuk sediaan krim yang berkhasiat sebagai antioksidan dengan tipe emulsi M/A. SLM yang digunakan adalah SLM yang sudah dikarakterisasi, hasil penetapan kadar flavonoid total daun kersen (Muntingia calabura L.) yaitu $4,31 \%$ yang dibuat dalam SLM dengan konsentrasi 3\%. Efisiensi penjerapan yang diperoleh $85,75 \%$ dengan ukuran partikel 5-20 $\mu \mathrm{m}$.

Keuntungan sediaan krim tipe M/A yaitu memberikan tingkat kenyamanan dalam penggunaannya, tidak lengket, memberikan efek melembabkan kulit serta memiliki kemampuan penyebaran yang baik (Ansel, 1989). Krim diformulasi dengan menggunakan variasi stiffening agent yaitu setil alcohol dengan konsentrasi F1 (2\%), F2 $(4 \%)$ dan F3 (6\%) variasi konsentrasi dipilih berdasarkan range penggunaan setil alkohol 2-10\% (Rowe et al., 2009).

Stiffening agent merupakan suatu zat yang ditambahkan kedalam suatu formula, yang berfungsi sebagai bahan pengental atau pengeras dalam formula krim yang akan mempertahankan konsistensi sediaan, tujuan variasi setil alkoholsebagai stiffening agent untuk melihat pengaruh viskositas terhadap stabilitas sediaan yang akan mempengaruhi laju difusi sediaan krim.

Evaluasi stabilitas fisik sediaan dalam penelitian ini dilakukan sebelum dan sesudah kondisi penyimpanan dipercepat. Krim dievaluasi yang terdiri dari beberrapa parameter yaitu organoleptik, homogenitas, $\mathrm{pH}$, viskositas, daya sebar, daya lekat dan menentukan tipe emulsi dengan uji dispersi warna dan pengenceran. Selanjutnya dilakukan uji stabilitas pada suhu $5^{\circ} \mathrm{C}$ selama 12 jam dan $35^{\circ} \mathrm{C}$ selama 12 jam selama 10 siklus ( 1 siklus sama dengan 24 jam) menggunakan climatic chamber, kemudian dievaluasi kembali sesudah diberi kondisi penyimpanan dipercepat.

$$
\text { Hasil uji organoleptik Uji }
$$

organoleptik menunjukkan tidak ada perubahan sebelum dan sesudah penyimpanan dipercepat. Demikian juga pada uji homogenitas tidak terdapat partikel-partikel kasar. Pada hasil pengukuran $\mathrm{pH}$ ketiga sediaan menunjukkan adanya perubahan $\mathrm{pH}$. F1 berubah dari 5,05 menjadi $4,61, \mathrm{~F} 2$ dari 5,12 menjadi 4,58 dan F3 dari 5,19 menjadi 4,51 Akan tetapi masih memenuhi rentang $\mathrm{pH}$ kulit 4,5-6,5 sehingga aman digunakan secara topikal.

Pengujian viskosistas krim baik sebelum maupun sesudah penyimpanan dipercepat menunjukkan ketiga formula mengalami perubahan viskositas yaitu penurunan viskositas. Untuk pengujian daya sebar krim dilakukan dengan mengukur diameter sebar setelah penambahan beban. Hasil penelitian menunjukkan sebelum penyimpanan dipercepat hanya F3 yang memenuhi standar range yaitu $5-7 \mathrm{~cm}$ sedangkan sesudah penyimpanan dipercepat terjadi peningkatan nilai daya sebar. Pada pengujian daya lekat. Ketiga formula meunjukkan daya lekat yang tidak berbeda jauh dengan rentang waktu sebelum penyimpanan dipercepat $16-20$ detik sedangkan setelah penyimpanan 12 18 detik.

Penentuan tipe emulsi baik sebelum maupun sesudah penyimpanan dipercepat menunjukkan tipe emulsi yang terbentuk adalah emulsi minyak dalam air, ketiga formula krim mudah diencerkan dengan penambahan air dan mudah terdispersi dengan penambahan metilen blue. 


\section{PEMBAHASAN}

Evaluasi krim berdasarkan metode uji dipercepat merupakan simulasi perjalanan suatu sediaan farmasi pada saat didistribusikan, dimana sediaan akan berada pada suatu tempat yang berbeda dan tempat tersebut dapat memiliki kondisi/suhu yang berbeda.

Hasil uji organoleptik dan uji homogenitas menunjukkan tidak terjadi perubahan baik sebelum maupun sesudah penyimpanan dipercepat untuk semua formula krim. Pada pengukuran $\mathrm{pH}$, terjadi perubahan $\mathrm{pH}$ setelah penyimpanan dipercepat pada semua formula namun masih berada dalam range $\mathrm{pH}$ yang dipersyaratkan sediaan krim dan $\mathrm{pH}$ kulit yaitu 4,5-6,5 (Swastika et al., 2013), $\mathrm{pH}$ sediaan harus memenuhi persyaratan $\mathrm{pH}$ kulit agar tidak menimbulkan iritasi pada saat pemakaian.

Pengujian viskositas menunjukkan terjadi peningkatan viskositas dengan meningkatnya jumlah setil alkohol sebagai stiffening agent untuk mempertahankan konsistensi sediaan. Setelah penyimpanan dipercepat, terjadi penuruan viskositas pada ketiga formula. Hal ini sejalan dengan hasil pengujian daya sebar, terjadi peningkatan daya sebar setelah penyimpanan dipercepat sehubungan dengan penurunan viskositas yang terjadi. Uji daya lekat juga menunjukkan terjadinya penurunan daya lekat setelah penyimpanan dipercepat pada ketiga formula. Uji daya lekat krim dilakukan untuk mengetahui kemampuan krim melekat pada tempat aplikasinya. Ketika viskositas sediaan krim menurun akan berpengaruh pada daya lekat dan daya sebar sediaan pada kulit sehingga mempengaruhi laju difusi zat aktif (Swastika et al., 2013). Namun perubahan daya lekat dan daya sebar masih memenuhi persayaratan yang ditetapkan. Pada pengujian tipe emulsi juga tidak terjadi inverse fase setelah penyimpanan dipercepat yaitu krim tipe m/a.

\section{KESIMPULAN}

Solid lipid microparticle ekstrak etanol daun kersen (Muntingia calabura L.) dapat dibuat dalam sediaan krim tipe M/A. Ketiga formula krim solid lipid microparticle ekstrak etanol daun kersen (Muntingia calabura L.) dengan konsetrasi yaitu F1 2\%, F2 4\% dan F3 6\% memenuhi persyaratan stabilitas fisik sebelum dan sesudah penyimpanan dipercepat meliputi organoleptik, homogenitas, $\mathrm{pH}$, Viskositas, daya lekat dan daya sebar dan tidak terjadi perubahan tipe emulsi.

\section{SARAN}

Perlu dilakukan uji lanjutan mengetahui apakah solid lipid microparticle ekstrak etanol daun kersen (Muntingia calabura L.) mampu melindungi zat yang terkandung dalam ekstrak dan melakukan optimasi pembuatan SLM dalam jumlah yang lebih besar.

\section{DAFTAR PUSTAKA}

Asdar, M. 2015. Formulasi dan Evaluasi Solid Lipid Microparticle Ekstrak Etanol Daun Kersen (Muntingia calabura L.) Sebagai Antioksidan. Sekolah Tinggi IImu Farmasi: Makassar.

Chengyu Gu, H.Caibiao, M.Chaolong, F.Qiao, X.Tingkang, dan X.Qiang. 2016. Development and Characterization of Solid Lipid Microparticles Cpntaining Vitamin C for Topical and Cosmetic use. Southeast University : China.

Fatmawaty, A., Nisa M., Riski R. 2015. Teknologi Sediaan Farmasi. Yogyakarta: Deepublish.

Genatrika E., Nurkhikmah I., dan Hapsari I. 2016. Formulasi sediaan krim minyak jintan hitam (Nigella sativa L.) Sebagai antijerawat terhadap bakteri Propionibacterium acnes. Universitas Muhammadiyah: Purwokerto.

Imrawat.i, Mus S., Gani, A.S, dan Bubua I.K. 2017. Antioxidant Activity Of Ethyl Acetate Fraction Of Muntingia calabura L. Leaves. Sekolah Tinggi IImu farmasi: Makassar. 2(2): 59-62.

Kuntorini, E.M, Setya F., Maria D.A. 2013. Struktur Anatomi dan UjiAktivitas Antioksidan Ekstrak Metanol Daun Kersen (Muntingia calabura L.). Universitas Lambung Mangkurat: Lampung.

Lachman L., Lieberman H.A., dan Kanig J.L. 1994. Teori dan Praktek Farmasi Industri. UI Press : Jakarta.

Puspitasari, D.A dan Wulandari, L.R. 2017. Aktivitas Antioksidan, Penetapan Kadar Fenolik Total dan Flavanoid Total Ekstrak Daun Kersen (Muntingia calabura L.). Universitas Wahid Hasyim: Semarang. Vo.7, No.2. 
Roy, A., Choudhury, A., Verma, A. 2014. Phytosome : A Novel Form For Herbal Drug Dellivery. Journal of Applied Pharmaceutical Research : Columbia.

Sami, F,J., Nur, S., Ramli N., dan B.Sutrisno. 2017. Uji Aktivitas Antioksidan Daun Kersen (Muntingia calabura L.) Dengan Metode DPPH (1,1-difenil-2-pikrilhidrazil) dan FRAP (Ferric Reducing Antioxidan Power). Sekolah Tinggi IImu Farmasi: Makassar.

Sari, N. A. 2015. Antioksidan Alternatif Untuk Menangkal Bahaya Radikal Bebas Pada Kulit. Universitas Islam Negeri Ar Raniry: Banda Aceh.
Sayuti K, Yenrina R. 2015. Antioksidan Alami dan Sintetik. Andalas University Press: Padang.

Swastika A., Mufrod, P. 2013. Aktivitas Antioksidan Krim Ekstrak Sari Tomat (Solanum iycopersicum L.). Universitas Gadjah Mada: Yogyakarta.

Voight R. 1994. Buku Pelajaran Teknologi Farmasi. Edisi Ke-5. Diterjemahkan Oleh: Dr Soendi Noerono. Gadjah Mada University Press: Yogyakarta. 
Tabel 1.

Formula KrimSLM

\begin{tabular}{cccc}
\hline \multirow{2}{*}{ Nama Bahan } & \multicolumn{3}{c}{ Jumlah (\%) } \\
\cline { 2 - 4 } & $\mathrm{F} 1$ & $\mathrm{~F} 2$ & $\mathrm{~F} 3$ \\
\hline Solid Lipid & 3 & 3 & 3 \\
Microparticle & 5 & 5 & 5 \\
Asam Stearat & 5 & 4 & 6 \\
Setil Alkohol & 2 & 6 & 6 \\
Parafin Cair & 6 & 15 & 15 \\
Propilenglikol & 15 & 3 & 3 \\
Span 60 & 3 & & \\
Tween 60 & & & \\
DMDM Hydantoin & 0,2 & 0,2 & 0,2 \\
Phenoxyetanol & 0,5 & 0,5 & 0,5 \\
Oleum Rosae & 0,1 & 0,1 & 0,1 \\
Alfa Tokoferol & 0,05 & 0,05 & 0,05 \\
Aquadest & $\mathrm{Ad}$ & $\mathrm{Ad}$ & $\mathrm{Ad}$ \\
& 100 & 100 & 100 \\
\hline
\end{tabular}

Tabel 2.

Hasil Pengamatan Uji Organoleptik

\begin{tabular}{clccccc}
\hline \multirow{2}{*}{ Formula } & \multicolumn{3}{c}{$\begin{array}{c}\text { Sebelum Penyimpanan } \\
\text { Dipercepat }\end{array}$} & \multicolumn{2}{c}{ Sesudah Penyimpanan Dipercepat } \\
\cline { 2 - 6 } & \multicolumn{1}{c}{ Warna } & Bau & Tekstur & Warna & Bau & Tekstur \\
\hline F1 & $\begin{array}{l}\text { Cokelat } \\
\text { Kehitaman }\end{array}$ & khas & $\begin{array}{l}\text { Setengah } \\
\text { Padat }\end{array}$ & $\begin{array}{l}\text { Cokelat } \\
\text { Kehitaman }\end{array}$ & Khas & Setengah Padat \\
\hline F2 & $\begin{array}{l}\text { Cokelat } \\
\text { Kehitaman }\end{array}$ & khas & $\begin{array}{l}\text { Setengah } \\
\text { Padat }\end{array}$ & $\begin{array}{l}\text { Cokelat } \\
\text { Kehitaman }\end{array}$ & Khas & Setengah Padat \\
\hline F3 & $\begin{array}{l}\text { Cokelat } \\
\text { Kehitaman }\end{array}$ & khas & $\begin{array}{l}\text { Setengah } \\
\text { Padat }\end{array}$ & $\begin{array}{l}\text { Cokelat } \\
\text { Kehitaman }\end{array}$ & Khas & Setengah Padat \\
& & & &
\end{tabular}

Keterangan:

F1 : krim dengan setil alkohol $2 \%$

F2 : krim dengan setil alkohol $4 \%$

F3 : krim dengan setil alkohol $6 \%$

Tabel 3.

Hasil pengamatan uji $\mathrm{pH}$

\begin{tabular}{ccc}
\hline Formula & $\begin{array}{c}\text { Sebelum Penyimpanan } \\
\text { Dipercepat }\end{array}$ & $\begin{array}{c}\text { Sesudah Penyimpanan } \\
\text { Dipercepat }\end{array}$ \\
\hline F1 & 5,05 & 4,61 \\
\hline F2 & 5,12 & 4,58 \\
\hline F3 & 5,19 & 4,51 \\
\hline
\end{tabular}

Keterangan:

F1 : krim dengan setil alkohol $2 \%$

F2 : krim dengan setil alkohol $4 \%$

F3 : krim dengan setil alkohol $6 \%$ 
Tabel 4.

Hasil pengamatan uji viskositas

\section{Keterangan:}

\begin{tabular}{ccc}
\hline Formula & $\begin{array}{c}\text { Sebelum Penyimpanan } \\
\text { Dipercepat }(\mathrm{cp})\end{array}$ & $\begin{array}{c}\text { Sesudah Penyimpanan } \\
\text { Dipercepat }(\mathrm{cp})\end{array}$ \\
\hline $\mathrm{F} 1$ & 138000 & 84000 \\
\hline $\mathrm{F} 2$ & 146000 & 112000 \\
\hline F3 & 156000 & 118000 \\
\hline
\end{tabular}

F1 : krim dengan setil alkohol $2 \%$

F2 : krim dengan setil alkohol $4 \%$

F3 : krim dengan setil alkohol $6 \%$

Tabel 5 .

Hasil pengamatan uji daya lekat

\begin{tabular}{ccc}
\hline Formula & $\begin{array}{c}\text { Sebelum Penyimpanan } \\
\text { Dipercepat (detik) }\end{array}$ & $\begin{array}{c}\text { Sesudah Penyimpanan } \\
\text { Dipercepat (detik) }\end{array}$ \\
\hline F1 & 16 & 12 \\
\hline F2 & 17 & 15 \\
\hline F3 & 20 & 18 \\
\hline
\end{tabular}

Keterangan:

F1 : krim dengan setil alkohol $2 \%$

F2 : krim dengan setil alkohol $4 \%$

F3 : krim dengan setil alkohol $6 \%$ 